On the next day the pupil was three-quarters dilated, and the chemosis was rapidly disappearing. On the 29th (two days after anaesthetic) there appeared early signs of traumatic cataract, with a slight increase in tension. The next day a small amount of lens matter was protruding into the anterior chamber. On October 2 the eye was almost quiet, and the pupil was fully dilated. On the 5 th the traumatic cataract was stationary. The following day the patient was shipped to England with notes and a supply of atropin drops. I was later informed that the eye had been excised in England on October 12, 1914.

It is to be regretted that fuller notes were not taken nor an X-ray examination made. Pressure of work at that period is, I think, sufficient excuse. I am of opinion that there was no foreign body in the eye and that the eye was excised in the fear of sympathetic affection in the other eye. This procedure occurred, I fear, on more than one occasion in the early days of the war. I can find no notes referring to the state of the light projection, although perception was present when the patient left my care.

\title{
PHLYCTENULAR CONJUNCTIVITIS AND ADENOIDS
}

BY

\author{
George Milne, M.D., D.P.H., \\ CAPTAIN R.A.M.C.
}

LATE CHIEF CLINICAL ASSISTANT MOORFIELDS EYE HOSPITAL

THE following two cases are of interest in connection with Captain Hird's article on "Phlyctenular disease and its relation to Tuberculosis," in the April number of The BRItish Journal of OPHTHALMOLOGY.

CASE 1.-W. G., a boy, 4 years old, was brought to me by his mother, who stated that he had been in his present condition for the last eighteen months. $\mathrm{He}$ had been at irregular intervals attending the out-patient department of more than one London Hospital without any apparent relief. He had intense photophobia and blepharospasm, much injection of his conjunctivae, and typical raised phlyctens in both eyes. Atropin ointment was ordered and a week later his refraction was estimated showing low hypermetropia and astigmatism (about $1 \mathrm{D}$.). Correcting glasses were ordered to be worn constantly. Syr. ferri iodidi was given internally and weak yellow ointment locally, and the mother was advised to keep the boy out of doors as much as possible. At the end of a month there was no appreciable improvement.

The boy then had an attack of acute follicular tonsillitis. This 
left him with enlarged tonsils and cervical glands, and, what I had not noticed before, definite symptoms of adenoids.

I advised the removal of the tonsils and adenoids. This was done six weeks after his attack of tonsillitis. His tonsils were guillotined and the adenoids thoroughly removed; all this time there had been no change in his eye condition.

The morning after the operation, to everybody's surprise, he was sitting up at the window looking at his picture books with no trace of photophobia, blepharospasm, or lacrymation, and no abnormal injection of his conjunctivae. The phlyctens had not quite disappeared, but within three days nothing abnormal, apart from some faint corneal scarring, could be detected. His eyes have remained perfectly well now for a year. I have seen him running about without his glasses.

CASE 2.-K. Mc., aged 11 years, had been under treatment for fifteen months for headache, photophobia, and lacrymation. One pair of glasses had been prescribed for her at hospital six months ago without any relief. On examination she had well-marked phlyctens on her left bulbar conjunctiva. Under atropin I found her to have hypermetropia in both eyes with astigmatism also in the left eye. Her glasses were correct. She had enlarged tonsils, enlarged cervical glands, and nasal catarrh. Her mother said she slept with her mouth open and snored. I ordered general tonic treatment, stopped school and all near work for the eyes, and tried the usual local remedies without any improvement at the end of two months. I stopped all treatment and a fortnight later removed her tonsils (guillotined) and adenoids. In less than three weeks the eye condition had cleared up entirely. I saw her after three months' stay at Margate; the glands in the neck persist and are undoubtedly now tubercular. Her eyes gave no further trouble. This case was still under treatment when I joined the R.A.M.C.

Remarks.-I am quite convinced that the removal of the adenoids and tonsils was the cause of the rapid recovery of the eye condition in both cases.

The conjunctiva, cornea, and posterior nares are dependent on the fifth cranial nerve for sensation. The presence of adenoids and the associated naso-pharyngeal catarrh was apparently reflexly responsible for the intense photophobia and lacrymation in Case 1. The difference in the clinical picture the day after the operation was remarkable. In this case all treatment for the eyes had been suspended when the boy had his attack of tonsillitis, and in Case 2 it was stopped so as to note the effect of the operation on the eye condition. Sixty-three per cent. of Captain Hird's cases had enlarged cervical glands, the majority of which he regarded as tubercular, and the others as due to infection through the teeth.

My experience, during three years' medical inspection of school 
children, was that over eighty per cent. of all cases with enlarged cervical glands in children had definite signs of adenoids. The mothers attributed the glands to various causes, viz., "sore throats," tonsillitis, repeated colds in the head, after-effects of measles or scarlet fever. They also gave a history of earache, deafness, discharge from ears or nasal catarrh. The presence of adenoids was confirmed by palpating the nasal pharynx. The tonsils were in most cases hypertrophied. This condition, if untreated, forms a suitable soil on which the tubercle bacillus may become implanted; the cervical glands, bronchial glands, and eventually the lungs may become involved; the child may get an attack of phlyctenular conjunctivitis.

Tuberculosis is recognized by ophthalmic surgeons as an important factor in the causation of phlyctenular conjunctivitis. . In Case 2 the phlyctens cleared up completely without any improvement in the glandular enlargement, in fact the tubercular process progressed. Had the adenoids been removed earlier, one felt that both the tubercular glands and the phlyctenular conjunctivitis might have been prevented. My reason for publishing these cases is to draw attention to the necessity for careful examination of the throat in all cases of phlyctenular conjunctivitis, and to advocate the early removal of the adenoids, which I consider an important step in the prevention of tubercular cervical adenitis as well as an effective means of treating and preventing the recurrence of phlyctenular conjunctivitis in cases which resist the ordinary methods of treatment.

\section{COUNCIL OF BRITISH OPHTHALMOLOGISTS}

\section{Report on the teaching and examination of medical students in ophthalmology}

THE Council have considered the question of the teaching and examination in Ophthalmology before qualification, and report as follows :

PART I.-Representations to the General Medical Council on the subject.

PART II.-Existing regulations concerning the teaching and examination in ophthalmology in the United Kingdom and abroad.

PART III.- The need for improved instruction of medical students in ophthalmology.

PART IV.-Summary of recommendations. 